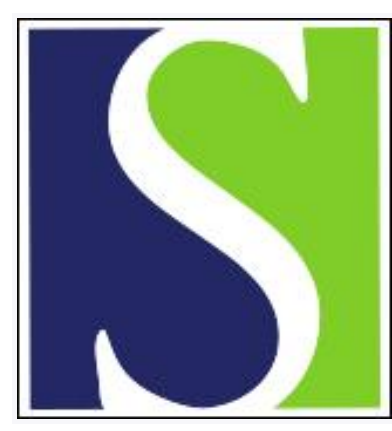

Scand J Work Environ Health 1981;7(3):239-240

https://doi.org/10.5271/sjweh.3118

Issue date: Sep 1981

\section{Laryngeal cancer and pickling house vapors}

by Ahlborg Jr G, Hogstedt C, Sundell L, Åman C-G

Affiliation: Department of Occupational medicine, Regional Hospital, S-701 85 Örebro, Sweden.

Key terms: cancer; laryngeal cancer; larynx; letter to the editor; pickling house; pickling house vapor; vapor

This article in PubMed: www.ncbi.nlm.nih.gov/pubmed/20120591

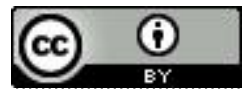




\section{Laryngeal cancer and pickling house vapors}

Laryngeal cancer is overrepresented among smokers and among persons with excessive consumption of alcohol $(3,4)$, but it has also been associated with occupational exposures such as asbestos (2) and diethyl sulfate (1). Chemical operators with mixed exposures had an increased risk of laryngeal cancer in a register study (5). Now we would like to report on three cases of medium, differentiated squamous laryngeal cancer diagnosed between 1971 and 1978 among men with mixed exposure in a small factory unit for the pickling and processing of stainless steel pipes.

The men were 53, 56 and 67 a old when the malignancies were diagnosed and are still alive after surgical treatment. The time from the beginning of employment at this unit until diagnosis was 19 a in two cases and $21 \mathrm{a}$ in the third. All three had been moderate smokers (10-15 cigarettes/d) for many years.

Two men had been working at a site where the pipes were drawn to smaller dimensions, and the third man's job was to cut these pipes at the end of the same size-reducing, drawing bench. Totally, only five to ten persons were occupied at the same time at this particular site. However, the drawing bench was situated in a larger pickling house where another 20-30 persons worked at the same time.

\section{Exposure}

Before the size of the stainless steel pipes was reduced at the drawing bench, the pipes were annealed and treated in different pickling baths containing sulfuric and nitric acid during the 1950 s and oxalic acid, ammonium bifluoride, and soap during the 1960s and 1970s. The pipes were degreased with sodium thiosulfate and sodium hydrosulfite. Moderate heat was generated in the size-reducing process $\left(100-150^{\circ} \mathrm{C}\right)$. Insignificant amounts of chromium and nickel have been measured in the workroom air $\left(0.04\right.$ and $0.01 \mathrm{mg} / \mathrm{m}^{3}$, respectively). The hydrogen fluoride concentrations for the pickling bath operators have been about $0.1-1.0 \mathrm{mg} / \mathrm{m}^{3}$, but the air concentrations at the drawing bench have been considerably lower. An oven for heating the pipes used to contain some asbestos strings, but the asbestos fiber concentrations in the air must have been very low.

\section{Epidemiology}

Altogether 181 men had been employed in the pickling house between 1951 and 1979 , 110 for more than 1 a. Sex, calendar year, and the age-class specific expectancy values for respiratory cancer incidences were calculated from the Swedish Cancer Register, 1958-1979 - with and without a requirement of 10 a of induction-latency time. Four respiratory malignancies had occurred (one bronchial carcinoma was found in addition to the three laryngeal cancers), but only about 0.6 were expected (table 1). The expectancy values for laryngeal cancer in the much smaller group directly involved in the reducing and cutting processes would be much lower.

\section{Discussion}

The clustering of three laryngeal cancers in this pickling house may be due to

Table 1. Observed and expected incidence of respiratory cancer, 1958-1979, among male workers with at least 1 a of employment calculated without (110 men: 1,458 person years) and with (78 men: 849 person years) a requirement of 10 a of induction-latency time.

\begin{tabular}{|c|c|c|c|c|c|}
\hline \multirow{2}{*}{$\begin{array}{l}\text { ICD a } \\
\text { number }\end{array}$} & \multirow{2}{*}{ Site } & \multicolumn{2}{|c|}{$\begin{array}{l}\text { Without induction- } \\
\text { latency time }\end{array}$} & \multicolumn{2}{|c|}{$\begin{array}{l}>10-a \text { induction- } \\
\text { latency time }\end{array}$} \\
\hline & & Observed & Expected & Observed & Expected \\
\hline $\begin{array}{l}160-163 \\
161\end{array}$ & $\begin{array}{l}\text { Respiratory tract } \\
\text { Larynx }\end{array}$ & $\begin{array}{l}4 \\
3\end{array}$ & $\begin{array}{l}0.66 \\
0.06\end{array}$ & $\begin{array}{l}4 \\
3\end{array}$ & $\begin{array}{l}0.55 \\
0.05\end{array}$ \\
\hline
\end{tabular}

a $I C D=$ International Classification of Diseases. 
chance in spite of the small expectancy values, but there is also a possibility of a causal relation between the different exposures and the cancer cases. Such a relation could possibly be an effect of the combination of irritative acid vapors, traces of carcinogenic metal compounds, and asbestos, plus the fact that all three cases were moderate smokers. There were no possibilities to evaluate any single factor in this group. However, we hope this letter might stimulate further reports and investigations on the incidence of respiratory cancers, particularly laryngeal cancer, in groups with similar exposures.

\section{References}

1. Lynch J, Hanis NM, Bird MG, Murray KJ, Walsh JP. An association of upper respiratory cancer with exposure to diethyl sulfate. J occup med 21 (1979) 333-341.

2. Morgan RW, Shettigara PT. Occupational asbestos exposure, smoking and laryngeal carcinoma. Ann ny acad sci 271 (1976) $308-310$.
3. Rothman KJ, Cann CJ, Flanders D, Fried MP. Epidemiology of laryngeal cancer. Epidemiol rev 2 (1980) 195-209.

4. US Department of Health Education and Welfare. Smoking and health - A report of the Surgeon General. US Government Printing Office, Washington, DC 1979, pp $1-16$.

5. Viadana E, Bross ID, Houten L. Cancer experience of men exposed to inhalation of chemicals or to combustion products. $\mathrm{J}$ occup med 18 (1976) $787-792$.

Gunnar Ahlborg Jr, MD, ${ }^{1}$ Christer Hogstedt, MD, ${ }^{1}$ Lennart Sundell, MD, ${ }^{1}$ CarlGöran Åman, $\mathrm{MD}^{2}$

1 Department of Occupational Medicine, Regional Hospital, S-70185 Örebro, Sweden.

2 Stockholm Transport Authorities, Department of Industrial Health, Munkbrogatan 4, S-111 27 Stockholm, Sweden. 